\title{
Sodium Restriction in Patients With CKD: A Randomized Controlled Trial of Self-management Support
}

\author{
Yvette Meuleman, MSc, ${ }^{1,2}$ Tiny Hoekstra, MSc, PhD, ${ }^{3,4}$ Friedo W. Dekker, MD, PhD, ${ }^{3}$ \\ Gerjan Navis, MD, PhD, ${ }^{5}$ Liffert Vogt, MD, PhD, ${ }^{6}$ Paul J.M. van der Boog, MD, PhD, ${ }^{7}$ \\ Willem Jan W. Bos, MD, PhD, ${ }^{8}$ Gert A. van Montfrans, MD, PhD, ${ }^{6}$ and \\ Sandra van Dijk, MSc, PhD, ${ }^{1,7}$ on behalf of the ESMO Study Group*
}

\footnotetext{
Background: To evaluate the effectiveness and sustainability of self-managed sodium restriction in patients with chronic kidney disease.

Study Design: Open randomized controlled trial.

Setting \& Participants: Patients with moderately decreased kidney function from 4 hospitals in the Netherlands.

Intervention: Regular care was compared with regular care plus an intervention comprising education, motivational interviewing, coaching, and self-monitoring of blood pressure (BP) and sodium.

Outcomes: Primary outcomes were sodium excretion and BP after the 3-month intervention and at 6-month follow-up. Secondary outcomes were protein excretion, kidney function, antihypertensive medication, self-efficacy, and health-related quality of life (HRQoL).

Results: At baseline, mean sodium excretion rate was $163.6 \pm 64.9$ (SD) mmol/24 h; mean estimated glomerular filtration rate was $49.7 \pm 25.6 \mathrm{~mL} / \mathrm{min} / 1.73 \mathrm{~m}^{2}$; median protein excretion rate was 0.8 (IQR, 0.41.7) $\mathrm{g} / 24 \mathrm{~h}$; and mean 24-hour ambulatory systolic and diastolic BPs were $129 \pm 15$ and $76 \pm 9 \mathrm{~mm} \mathrm{Hg}$, respectively. Compared to regular care only $(n=71)$, at 3 months, the intervention group $(n=67)$ showed reduced sodium excretion rate (mean change, $-30.3[95 \% \mathrm{Cl},-54.7$ to -5.9$] \mathrm{mmol} / 24 \mathrm{~h}$ ), daytime ambulatory diastolic BP (mean change, $-3.4[95 \% \mathrm{Cl},-6.3$ to -0.6$] \mathrm{mm} \mathrm{Hg}$ ), diastolic office BP (mean change, $-5.2[95 \% \mathrm{Cl},-8.4$ to -2.1$] \mathrm{mm} \mathrm{Hg}$ ), protein excretion (mean change, $-0.4[95 \% \mathrm{Cl},-0.7$ to $-0.1] \mathrm{g} / 24 \mathrm{~h}$ ), and improved self-efficacy (mean change, 0.5 [95\% Cl, 0.1 to 0.9$]$ ). At 6 months, differences in sodium excretion rates and ambulatory BPs between the groups were not significant, but differences were detected in systolic and diastolic office BPs (mean changes of $-7.3[95 \% \mathrm{Cl},-12.7$ to -1.9$]$ and $-3.8[95 \% \mathrm{Cl},-6.9$ to -0.6$] \mathrm{mm} \mathrm{Hg}$, respectively), protein excretion (mean changes, $-0.3[95 \% \mathrm{Cl}$, -0.6 to -0.1$] \mathrm{g} / 24 \mathrm{~h}$ ), and self-efficacy (mean change, $0.5[95 \% \mathrm{Cl}, 0.0$ to 0.9$]$ ). No differences in kidney function, medication, and HRQoL were observed.

Limitations: Nonblinding, relatively low response rate, and missing data.

Conclusions: Compared to regular care only, this self-management intervention modestly improved outcomes, although effects on sodium excretion and ambulatory BP diminish over time.

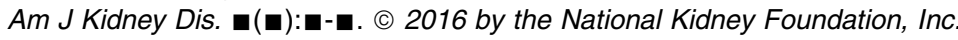

INDEX WORDS: Behavior change; dietary sodium intake; blood pressure; chronic kidney disease (CKD); health-related quality of life (HRQoL); hypertension; kidney function; lifestyle interventions; nutrition; protein excretion; randomized controlled trial; self-efficacy; self-managment support; disease progression; modifiable risk factor.
}

$\mathbf{S}^{\mathrm{s}}$ riving for a maximum daily sodium intake of $2,000 \mathrm{mg}$ is an important treatment goal in patients with chronic kidney disease $(\mathrm{CKD})^{1}$ because it can improve health outcomes. ${ }^{2,3}$ However, despite the efforts of health care professionals, most patients with CKD do not reach the recommended sodium intake. $^{4}$

Nonadherence to the sodium treatment guideline seems to be a complex problem because previous studies have shown that patients with CKD face
From the ${ }^{1}$ Department of Health, Medical, and Neuropsychology, Institute of Psychology, Leiden University; Departments of ${ }^{2}$ Medical Psychology and ${ }^{3}$ Clinical Epidemiology, Leiden University Medical Center, Leiden; ${ }^{4}$ Department of Nephrology, $V U$ University Medical Center, Amsterdam; ${ }^{5}$ Department of Nephrology, University Medical Center Groningen, Groningen; ${ }^{6}$ Department of Internal Medicine, Academic Medical Center, Amsterdam; ${ }^{7}$ Department of Nephrology, Leiden University Medical Center, Leiden; and ${ }^{8}$ Department of Internal Medicine, Sint Antonius Hospital, Nieuwegein, the Netherlands.

*A list of the Effects of Self-monitoring on Outcome of Chronic Kidney Disease (ESMO) Study Group members appears in the Acknowledgements.
Received May 3, 2016. Accepted in revised form August 25, 2016.

Trial registration: www.TrialRegister.nl; study number: NTR2917.

Address correspondence to Yvette Meuleman, MSc, Leiden University, Department of Health, Medical and Neuropsychology, Wassenaarseweg 52, 2300 RB Leiden, the Netherlands. E-mail: meulemany@fsw.leidenuniv.nl

(C) 2016 by the National Kidney Foundation, Inc.

0272-6386

http://dx.doi.org/10.1053/j.ajkd.2016.08.042 
multiple barriers when reducing sodium intake, ${ }^{5,6}$ including insufficient motivation, knowledge, feedback, coping skills, and personal goal setting. Hence, to successfully change lifestyle, theory-based selfregulation interventions that encompass multiple behavior change techniques are required. ${ }^{7-11}$ However, such self-management interventions to support patients with CKD to overcome these barriers and incorporate the sodium guideline into their daily lives are lacking.

Until now, mostly crossover trials have been conducted; these studies have shown that if patients with CKD adhere to a low-sodium diet, important risk factors for disease progression can be reduced, ${ }^{12,13}$ including blood pressure (BP) and protein excretion. ${ }^{14-17}$ However, these studies did not include behavioral approaches needed for long-term adherence and only evaluated efficacy directly after relatively brief (2-6 weeks) and strictly regulated interventions. Hence, they do not provide information about the effectiveness and sustainability of sodium interventions to support patients in real-life settings.

To our knowledge, there are only 2 pragmatic trials that included 24-hour urinary sodium excretion as an outcome parameter (ie, the gold standard ${ }^{18}$ ). First, De Brito-Ashurst et $\mathrm{al}^{19}$ reduced sodium intake by means of educational cooking sessions, but only evaluated effects immediately after the intervention. Second, the Multifactorial Approach and Superior Treatment Efficacy in Renal Patients With the Aid of Nurse Practitioners Study (MASTERPLAN) study aimed at strict implementation of multiple treatment guidelines with the aid of nurse practitioners, which led to increased medication adherence, but did not improve lifestyle adherence. ${ }^{20}$ Moreover, both interventions lacked a theoretical basis, were mainly education based, and included only a few behavior change techniques.

Therefore, we designed a 3-month self-management intervention based on self-regulation theory, ${ }^{21,22}$ encompassing various evidence-based behavior change techniques $^{7-11}$ to support patients with CKD in reducing their daily sodium intake. The aim of this Effects of Selfmonitoring on Outcome of Chronic Kidney Disease (ESMO) trial was to investigate whether the intervention would result in reduced sodium intake and improved health outcomes (eg, BP and protein excretion) directly after the 3-month intervention and at the 6-month followup. In addition, because the literature has shown that self-management interventions can improve patients' well-being, this study also aimed to improve healthrelated quality of life (HRQoL) ${ }^{23}$ and self-efficacy (ie, confidence in ability to manage the disease). ${ }^{24}$

\section{METHODS}

\section{Study Design}

This open randomized controlled trial was conducted from June 2011 to August 2014 at the nephrology departments of 3 university hospitals and 1 general teaching hospital in the Netherlands: Leiden University Medical Center, University Medical Center Groningen, Academic Medical Center Amsterdam, and Sint Antonius Hospital Nieuwegein. Written informed consent was obtained from all participants before inclusion. This study was approved by the medical ethics committees of all centers (P10.056) and complies with the Declaration of Helsinki. The CONSORT (Consolidated Standards of Reporting Trials) checklist was used as reference for reporting. ${ }^{25}$

\section{Participants and Randomization}

From June 2011 through March 2014, patients with moderately decreased kidney function and hypertension were recruited (Box 1 depicts all inclusion and exclusion criteria). Eligible patients received an invitation, information regarding the procedure and confidentiality, an informed consent form, and a baseline questionnaire. Upon receiving patients' written informed consent at the external data management center (Nefrovisie), a medical information specialist allocated patients to the intervention or control condition using a computer-based block randomization procedure. The number of patients in each condition was predefined, and different sizes of blocks were used to prevent too many patients being consecutively assigned to the same condition. Only the medical information specialist knew the block sizes. Thereafter, researchers and patients were notified of the allocation.

\section{Study Protocol}

Both groups received regular care according to the Dutch Federation of Nephrology treatment guidelines ${ }^{1}$ (based on NKFKDOQI [National Kidney Foundation-Kidney Disease Outcomes Quality Initiative] ${ }^{26}$ and KDIGO [Kidney Disease: Improving Global Outcomes] guidelines ${ }^{27}$ ). Regular care consisted of consultations with the nephrologist every 3 to 6 months

\section{Box 1. Inclusion and Exclusion Criteria}

\section{Inclusion criteria}

- Dutch speaking

- $\geq 18$ y

- Being treated by an internist

- Kidney function (eGFR) $\geq 20 \mathrm{~mL} / \mathrm{min} / 1.73 \mathrm{~m}^{2}$

- Protein excretion measurements $>0.2 \mathrm{~g} / \mathrm{L}$ or $0.3 \mathrm{~g} / 24 \mathrm{~h}$

- 2 recent sodium excretion measurements $\geq 120 \mathrm{mmol} / 24 \mathrm{~h}$

- $\mathrm{BP}>135 / 85 \mathrm{~mm} \mathrm{Hg}$ or controlled BP with the use of antihypertensive medication, among which at least 1 RAAS blockade

Exclusion criteria

- $\mathrm{BP}>180 / 100 \mathrm{~mm} \mathrm{Hg}$ or $<125 / 75 \mathrm{~mm} \mathrm{Hg}$

- Received a kidney transplant $<1$ y ago

- Diagnosed with type 1 diabetes mellitus

- Had acute kidney failure

- Accelerated kidney function decrease $>6 \mathrm{~mL} / \mathrm{min} /$ $1.73 \mathrm{~m}^{2}$ in previous year

- Had a cardiovascular event (ie, myocardial infarction or cerebrovascular event) $<6$ mo ago

- Diagnosed with malignancy $<5$ y ago (other than basal cell or squamous cell carcinoma of skin)

- Participating in other clinical trial that included medication

Note: Inclusion and exclusion criteria as approved by the medical ethics committee and described in the Netherlands Trial Registry (study number: NTR2917).

Abbreviations: BP, blood pressure; eGFR, estimated glomerular filtration rate; RAAS, renin-angiotensin-aldosterone system. 
and, if necessary, nutrition counseling by a dietician. Those who received only regular care were the control group.

Patients in the intervention group also received the 3-month selfmanagement intervention. During the intervention, patients were coupled with one of 4 personal coaches: 3 health psychologists and 1 dietician, all trained in motivational interviewing techniques. ${ }^{28}$ The intervention started with a 1-hour individual motivational interview at the patient's hospital, which focused on discussing barriers, benefits, and strategies for sodium reduction; setting personal sodium goals; and strengthening intrinsic motivation and self-efficacy. Thereafter, patients received education, a kidney-friendly cookbook, and instructions for self-monitoring BP (using a Microlife WatchBP Home device), dietary intake (using an online food diary; www. mijnnierinzicht.nl by Bonstato), and 24-hour urinary sodium excretion (using an innovative point-of-care chip-device [Medimate $\mathrm{BV}]) .{ }^{29}$ Patients were instructed to take measurements at least once a week in the first 6 weeks and, depending on patients' preferences, thereafter once every 2 or 3 weeks. Following these self-monitoring measurements (ie, with the same frequency), patients received feedback by telephone from their coach and discussed progression, achievements, barriers, and possible solutions. After 3 months, a final motivational interview took place that focused on evaluation and relapse prevention. For a detailed intervention description following the Coventry, Aberdeen and London Refined (CALO-RE) taxonomy of behavior change techniques, ${ }^{30}$ see Item S1. Finally, if desired, patients received information regarding social support, refusal skills, medication adherence strategies, physical exercise, healthy eating, smoking, and alcohol intake.

\section{Measurements and Outcomes}

\section{Data Acquisition}

Data were collected at baseline, directly after the 3-month intervention, and at the 6-month follow-up. Sociodemographic, anthropometric, and medical data were collected during hospital visits by individuals not blinded to treatment allocation, using a secured online Case Report Form. Biochemical data were extracted from hospital information systems. Psychosocial measures were acquired using self-report questionnaires. All data were collected and stored on a secured server under administration of the data management center.

\section{Primary Outcomes}

Sodium intake was estimated from 24-hour urinary sodium excretion. BP was measured with ambulatory BP monitoring using validated Spacelabs 90207 and 90217 devices. Monitors were programmed for 24 hours with 15-minute day intervals and 30minute night intervals. Recordings were corrected for patients' sleep-wake rhythm and considered satisfactory when meeting criteria of the European Society of Hypertension guidelines. ${ }^{31}$ Office BP was measured by taking the average of 3 measurements using Microlife WatchBP Home after 5 minutes of rest.

\section{Secondary Outcomes}

Because clinicians use different measures for kidney function, kidney function was measured as creatinine clearance corrected for body surface area (using the DuBois and DuBois ${ }^{32}$ formula) and estimated glomerular filtration rate (using the 4-variable MDRD [Modification of Diet in Renal Disease] Study equation ${ }^{33}$ ). Protein excretion was measured using 24-hour urinary protein excretion, and antihypertensive medication use was calculated by taking a sum score of the number of antihypertensive medications. HRQoL was assessed with the 36-Item Short Form Health Survey questionnaire. ${ }^{34}$ Scores for physical and mental HRQoL ranged from 0 to 100 , with higher scores indicating better HRQoL. The questionnaire showed good reliability, with Cronbach alpha values of 0.92 and 0.82 for physical and mental HRQoL, respectively.
Furthermore, self-efficacy was assessed by the Chronic Disease Self-Efficacy Scales-Manage Disease in General Scale. ${ }^{35}$ Scores ranged from 1 to 10 , with higher scores indicating a stronger belief in the capability of managing the disease. This questionnaire also showed good reliability, with a Cronbach alpha value of 0.73 . In addition, because body weight is often reduced after sodium interventions, ${ }^{15,36}$ body weight was also measured with shoes removed using the hospitals' calibrated digital scales.

\section{Power Calculation and Statistical Analysis}

To detect a difference of $4 \mathrm{~mm} \mathrm{Hg}$ in 24-hour systolic BP, ${ }^{37}$ with an estimated standard deviation of $7 \mathrm{~mm} \mathrm{Hg},{ }^{38}$ a 2-sided significance of 0.05 , and a power of $90 \%, 64$ patients were needed in each group. Taking into account a dropout rate of $15 \%$, we aimed to include 150 patients.

Descriptive statistics were computed to describe baseline characteristics. To investigate the effectiveness of the intervention, we focused on the effect of the study group over time using intention-to-treat analysis and linear mixed modeling. Assumptions for linear mixed modeling were valid for all outcomes. Models included the following fixed variables: group, time, and the various continuous dependent variables. Furthermore, models included patient-level random effects to account for correlation between patients' repeated measures over time. An interaction term was also included as fixed variable: group $\times$ time point, which indicated the effect (ie, change in scores for dependent variables) of the study group by time. To increase the precision of our estimates, models were adjusted for the baseline value. Because a linear mixed model takes into account missing outcomes but not missing covariates, missing baseline values were imputed using multiple imputation (using 10 repetitions) because we do not believe "missing not at random" was dominant. ${ }^{39}$ Several sensitivity analyses were performed to test the robustness of our results (Item S1; including primary analysis adjusted for baseline covariates, without adjustments, and as-treated analysis). Statistical analysis was performed using SPSS, version 22.0 (IBM).

\section{RESULTS}

\section{Participant Flow}

In total, 151 of $333(45.3 \%)$ eligible patients provided written informed consent. Hereafter, 138 patients started the allocated group and 26 patients dropped out during the trial, leaving 112 (74.2\%) patients who completed the allocated group. In total, 138 patients were included in the primary intentionto-treat analysis: 67 patients in the intervention group and 71 patients in the control group. Figure 1 depicts the participant flow.

\section{Baseline Characteristics}

In this sample of 138 patients, mean estimated glomerular filtration rate was $49.7 \pm 25.6$ (standard deviation) $\mathrm{mL} / \mathrm{min} / 1.73 \mathrm{~m}^{2}$ and median protein excretion rate was 0.8 (interquartile range, 0.4-1.7) $\mathrm{g} / 24 \mathrm{~h}$. In addition, mean 24-hour ambulatory systolic and diastolic BPs were $129 \pm 15$ and $76 \pm 9 \mathrm{~mm} \mathrm{Hg}$, respectively, and mean sodium excretion rate was $163.6 \pm 64.9 \mathrm{mmol} / 24 \mathrm{~h}$ (Table 1 ). Various differences between the intervention and control groups were observed (Item S2). 


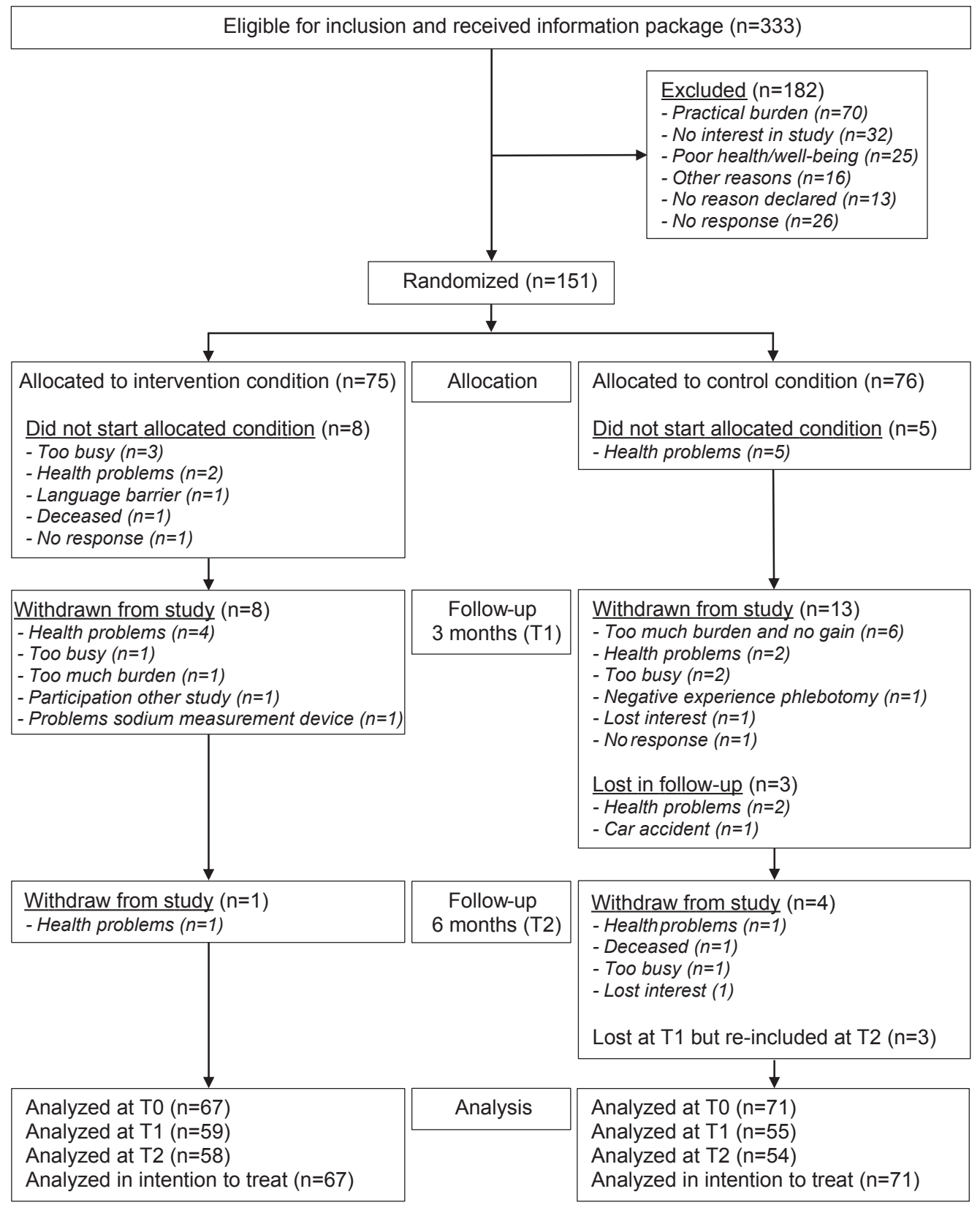

Figure 1. Participant flow.

\section{Patient Adherence, Goals, and Evaluation}

In total, 55 patients $(82.1 \%)$ received the intervention according to protocol. Four $(6 \%)$ patients did not attend the final interview, and $8(12 \%)$ patients did not attend the final interview and had fewer than 5 self-monitoring moments and consultations.

In addition to setting personal sodium goals, 21 (31\%) patients set weight-loss goals, $9(13 \%)$ patients set exercise goals, $1(2 \%)$ patient set a goal to reduce alcohol intake, and $3(5 \%)$ patients wanted to receive information regarding medication adherence strategies, social support, or refusal skills.
Patient satisfaction with the intervention was high: $42(63 \%)$ patients returned the evaluation questionnaire and gave the intervention a mean score of $7.9 \pm 0.9$ on a 10 -point scale, with higher scores indicating greater satisfaction. All separate intervention components (ie, education, motivational interviews, feedback consultations, and self-monitoring tools) were evaluated as very useful: mean scores ranged from $4.0 \pm 0.7$ to $4.7 \pm 0.6$ on a 5-point scale, with higher scores indicating greater usefulness. It is important to note that although the food diary and sodium measurement device were evaluated as very 
Table 1. Baseline Patient Characteristics

\begin{tabular}{|c|c|c|}
\hline Characteristic & Intervention $(n=67)$ & Control $(n=71)$ \\
\hline Age, y & $55.6 \pm 11.7$ & $54.7 \pm 16.0$ \\
\hline Male sex & $53(79)$ & $60(85)$ \\
\hline Dutch ethnicity & $59(88)$ & $66(93)$ \\
\hline Married or cohabiting & $59(88)$ & $53(75)$ \\
\hline Low education & $40(60)$ & $48(68)$ \\
\hline Paid job & $37(55)$ & $35(49)$ \\
\hline \multicolumn{3}{|l|}{ Primary cause of kidney failure ${ }^{a}$} \\
\hline Diabetes mellitus & $6(9)$ & $2(3)$ \\
\hline Glomerulonephritis & $16(24)$ & $14(20)$ \\
\hline Renal vascular disease & $16(24)$ & $21(30)$ \\
\hline Other cause & $29(43)$ & $34(48)$ \\
\hline Diabetes mellitus & $20(30)$ & $15(21)$ \\
\hline Cardiovascular disease $^{\mathrm{b}}$ & $24(36)$ & $28(39)$ \\
\hline Kidney transplant recipient ${ }^{\mathrm{C}}$ & $17(25)$ & $10(14)$ \\
\hline Sodium excretion rate, $\mathrm{mmol} / 24 \mathrm{~h}^{\mathrm{d}}$ & $151.1 \pm 66.9$ & $176.1 \pm 60.9$ \\
\hline Sodium-creatinine ratio, $\mathrm{mmol} / \mathrm{g}(24 \mathrm{~h})^{\mathrm{e}}$ & $103.7 \pm 44.4$ & $114.7 \pm 40.9$ \\
\hline Protein excretion rate, $g / 24 h^{f}$ & $0.70[0.33-1.33]$ & $0.91[0.41-2.16]$ \\
\hline eGFR, $\mathrm{mL} / \mathrm{min} / 1.73 \mathrm{~m}^{2 \mathrm{~g}}$ & $47.6 \pm 25.0$ & $51.8 \pm 26.2$ \\
\hline BSA-corrected $\mathrm{CL}_{\mathrm{cr}}, \mathrm{mL} / \mathrm{min} / 1.73 \mathrm{~m}^{2 \mathrm{~h}}$ & $46.0[32.3-69.3]$ & $55.1[40.1-81.8]$ \\
\hline Potassium excretion rate, $\mathrm{mmol} / 24 \mathrm{~h}^{\mathrm{i}}$ & $69.8 \pm 21.5$ & $73.5 \pm 28.1$ \\
\hline Hemoglobin, g/dL ${ }^{j}$ & $14.1 \pm 1.9$ & $13.7 \pm 1.5$ \\
\hline Total cholesterol, $\mathrm{mg} / \mathrm{dL}^{\prime}$ & $197.2 \pm 42.5$ & $193.3 \pm 38.7$ \\
\hline 24-hour SBP, mm Hg & $129 \pm 15$ & $128 \pm 15$ \\
\hline 24-hour DBP, $\mathrm{mm} \mathrm{Hg}^{\mathrm{k}, \mathrm{m}}$ & $77 \pm 10$ & $75 \pm 9$ \\
\hline Office SBP, mm Hg & $142 \pm 19$ & $137 \pm 17$ \\
\hline Office DBP, $\mathrm{mm} \mathrm{Hg}$ & $87 \pm 11$ & $83 \pm 10$ \\
\hline Body weight, $\mathrm{kg}$ & $90.9 \pm 15.7$ & $92.7 \pm 16.9$ \\
\hline Body mass index, $\mathrm{kg} / \mathrm{m}^{2}$ & $29.7 \pm 5.4$ & $29.7 \pm 5.2$ \\
\hline HRQoL-Physical $^{n}$ & $70.8 \pm 21.1$ & $65.2 \pm 24.3$ \\
\hline HRQoL-Mental $^{\circ}$ & $73.9 \pm 19.5$ & $72.0 \pm 18.1$ \\
\hline Self-efficacy ${ }^{p}$ & $7.5 \pm 1.3$ & $7.9 \pm 0.9$ \\
\hline Anti-HTN medication use & $64(96)$ & $70(99)$ \\
\hline Sum score anti-HTN medication & $2.3(1.2)$ & $2.4(1.1)$ \\
\hline RAAS blockade use & $50(75)$ & $60(85)$ \\
\hline ARBs & $27(40)$ & $27(38)$ \\
\hline ACE inhibitors & $27(40)$ & $37(52)$ \\
\hline Calcium channel blocker use & $26(39)$ & $29(41)$ \\
\hline$\beta$-Blocker use & $28(42)$ & $30(42)$ \\
\hline Diuretic use & $30(45)$ & $35(49)$ \\
\hline$\alpha_{1}$-Adrenergic blocker use & $8(12)$ & $3(4)$ \\
\hline Other anti-HTN medication use & $8(12)$ & $2(3)$ \\
\hline
\end{tabular}

Note: Values for categorical variables are given as count (proportion); values for continuous variables are given as mean \pm standard deviation for normally distributed variables or median [interquartile range] for skewed variables. Conversion factor for cholesterol in $\mathrm{mg} / \mathrm{dL}$ to $\mathrm{mmol} / \mathrm{L}, \times 0.02586$. Low education was classified as: primary education and lower secondary education.

Abbreviations: ACE, angiotensin-converting enzyme; ABPM, ambulatory blood pressure monitoring; ARBs, angiotensin II type 1 receptor antagonists; $\mathrm{BSA}$, body surface area; $\mathrm{CL}_{\mathrm{cr}}$, creatinine clearance; $\mathrm{DBP}$, diastolic blood pressure; eGFR, estimated glomerular filtration rate; HRQoL, health-related quality of life; HTN, hypertension; RAAS, renin-angiotensin-aldosterone system; SBP, systolic blood pressure.

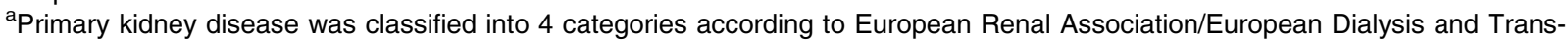
plant Association codes. ${ }^{50}$

${ }^{b}$ Cardiovascular disease was defined by the presence of angina pectoris, coronary disease, and/or myocardial infarction.

${ }^{\mathrm{c}}$ To meet inclusion criteria, transplantation had to have occurred $>1$ year prior to inclusion.

Complete data available with the exception of the following variables, with data available for: ${ }^{\mathrm{d}} 66$ intervention patients (99\%) and 66 control patients (93\%), ${ }^{\mathrm{e}} 65$ intervention patients (97\%) and 66 control patients (93\%), ${ }^{\mathrm{f}} 63$ intervention patients $(94 \%)$ and 66 control patients $(93 \%),{ }^{9} 64$ control patients $(90.1 \%),{ }^{\mathrm{h}} 65$ intervention patients $(97.0 \%)$ and 62 control patients $(87.3 \%)$, ${ }^{\mathrm{i}} 66$ intervention patients (99\%) and 65 control patients (92\%), ${ }^{\mathrm{j}} 65$ control patients (92\%), ${ }^{\prime} 64$ control patients $(90 \%),{ }^{\mathrm{m}} 58$ intervention patients $(87 \%)$ and 55 control patients $(78 \%),{ }^{n} 63$ intervention patients (94\%) and 70 control patients (99\%), ${ }^{\circ} 63$ intervention patients (94\%) and 69 control patients $(97 \%)$, and ${ }^{\mathrm{P}} 64$ intervention patients $(96 \%)$ and 69 control patients $(97 \%)$.

${ }^{\mathrm{k}} \mathrm{A}$ total of 133 complete ABPM measurements were available: 66 in the intervention group (99\%) and 67 in the control group (94\%). Following the guidelines for reliable ABPM measurements, recordings were blind evaluated and 20 ABPM measurements (15\%) were excluded from analyses (8 [12\%] in the intervention group and 12 [18\%] in the control group). 
useful, patients also had some frustration (both mean scores were $2.3 \pm 1.5$ on a 5-point scale [higher scores indicate higher levels of frustration]), which referred to the complexity of completing the food diary and to failures of the sodium measurement device (which meant that the procedure had to be repeated and, in a few cases, 24-hour urine had to be collected again or the device had to be replaced).

\section{Primary and Secondary Outcomes}

\section{At 3 Months}

Several significant differences were observed at the end of the intervention (Table 2). Compared to regular care alone, the intervention resulted in a $-30.3(95 \%$ confidence interval $[\mathrm{CI}],-54.7$ to -5.9$) \mathrm{mmol} / 24 \mathrm{~h}$ mean change in sodium excretion rate, $-3.4(95 \%$ $\mathrm{CI},-6.3$ to -0.6$) \mathrm{mm} \mathrm{Hg}$ mean change in daytime diastolic BP, $-5.2(95 \% \mathrm{CI},-8.4$ to -2.1$) \mathrm{mm} \mathrm{Hg}$ mean change in diastolic office $\mathrm{BP}$, and $-0.4(95 \%$ $\mathrm{CI},-0.7$ to -0.1$) \mathrm{g} / 24 \mathrm{~h}$ mean change in protein excretion rate. Furthermore, there was a 0.5 (95\% CI, 0.1-0.9) mean increase in self-efficacy score in the intervention group compared to the control group. No significant differences between groups were detected in antihypertensive medication, kidney function, and HRQoL. In addition, the intervention group had a reduction in body weight compared to the control group (mean change, $-1.5[95 \% \mathrm{CI},-2.7$ to -0.3$] \mathrm{kg}$ ).

\section{At 6 Months}

No significant differences in sodium excretion and ambulatory BP measurements were found at the 6month follow-up, but several other differences were observed (Table 2). Compared to regular care only, the intervention resulted in $-7.3(95 \% \mathrm{CI},-12.7$ to -1.9$)$ and $-3.8(95 \% \mathrm{CI},-6.9$ to -0.6$) \mathrm{mm} \mathrm{Hg}$ mean changes in systolic and diastolic office BPs, respectively, and a mean change of $-0.3 \quad(95 \%$ $\mathrm{CI},-0.6$ to -0.1$) \mathrm{g} / 24 \mathrm{~h}$ in protein excretion rate. There was a $0.5(95 \% \mathrm{CI}, 0.0-0.9)$ mean increase in self-efficacy score in the intervention group compared to the control group. No significant differences between groups were detected in antihypertensive medication, kidney function, and HRQoL. In addition, there was a reduction in body weight in the intervention group compared to the control group (mean change, -1.7 [95\% CI, -2.9 to -0.5$] \mathrm{kg}$ ).

All within- and between-group effects are shown in Table 2, Fig 2 (sodium excretion, protein excretion, and systolic and diastolic 24-hour BPs), and Fig S1 (all other outcomes).

Finally, sensitivity analysis showed that most results remained stable, including the analysis adjusted for baseline covariates, the analysis without adjustments, and as-treated analysis (Item S2).

\section{DISCUSSION}

To our knowledge, ESMO is the first study to investigate whether sodium intake in patients with CKD can be changed by means of a theory-based selfmanagement intervention and to evaluate not only the effectiveness, but also the sustainability of this reallife intervention. Results indicate that compared to regular care only, this behavioral approach can modestly decrease risk factors for disease progression in patients with CKD. However, effects on the primary outcomes - sodium excretion and ambulatory $\mathrm{BP}$-following the intervention diminish over time.

The findings of this study are partly in agreement with previous research. In contrast to the MASTERPLAN study, ${ }^{20}$ but in accordance with the study of de Brito-Ashurst et al, ${ }^{19}$ we found that sodium intake in patients with CKD can be modified by means of a self-management intervention. Compared to the intervention effect of De BritoAshurst et $\mathrm{al}^{19}$ of $103 \mathrm{mmol} / 24 \mathrm{~h}$, our reduction of $30 \mathrm{mmol}$ could be considered modest. Compared to the Trials of Hypertension Prevention (TOHP) II study, which evaluated a multifactorial sodium intervention in overweight nonhypertensive adults and found sodium reductions of 44 and $38 \mathrm{mmol} / 24 \mathrm{~h},{ }^{40}$ our sodium reduction could be considered similar but was not maintained for 6 months. Possible explanations for the discrepancies can be found in the intervention design.

First, our intervention was a low intensity intervention compared to the 3-year TOHP II intervention comprising more than 15 contact moments. ${ }^{40,41}$ Although evidence for intensity as a moderator for effectiveness of lifestyle interventions is inconclusive (eg, Greaves et $\mathrm{al}^{11}$ found intensity to be a moderator, but Janssen et $\mathrm{al}^{42}$ did not), increased intervention intensity might have resulted in maintaining the low-sodium diet. Second, our intervention could be regarded as an individual-oriented intervention compared to the De Brito-Ashurst et al $^{19}$ and TOHP II ${ }^{40}$ interventions, which comprised group meetings. Planning social support was part of our intervention and significant others were invited to attend meetings. However, only 23 (34\%) patients brought significant others, and social support among fellow-patients was not facilitated. Given that social support is associated with lifestyle adherence, ${ }^{11,43}$ increased social support might have led to stronger effects. Third, the intervention of De Brito-Ashurst et $\mathrm{al}^{19}$ included cooking lessons, whereas ESMO participants received a kidney-friendly cookbook. Perhaps including low-sodium cooking sessions instead of merely providing written instructions could have resulted in larger sodium reductions. Finally, the TOHP II intervention included an extended phase using 
Table 2. Intention-to-Treat Analysis Adjusted for Baseline Value

\begin{tabular}{|c|c|c|c|c|c|c|c|}
\hline \multicolumn{6}{|c|}{ Mean \pm Standard Error of Mean } & & \\
\hline \multicolumn{3}{|c|}{ Intervention Group } & \multicolumn{3}{|c|}{ Control Group } & \multicolumn{2}{|c|}{ Effect Intervention $(95 \% \mathrm{Cl})$} \\
\hline T0 & T1 & T2 & TO & T1 & T2 & $\Delta \mathrm{T} 0-\mathrm{T} 1$ & $\Delta \mathrm{T} 0-\mathrm{T} 2$ \\
\hline
\end{tabular}

Sodium

Blood pressure

24-hour SBP, $\mathrm{mm} \mathrm{Hg}$

24-hour DBP, $\mathrm{mm} \mathrm{Hg}$

Day SBP, $\mathrm{mm} \mathrm{Hg}$

Day DBP, $\mathrm{mm} \mathrm{Hg}$

Night SBP, $\mathrm{mm} \mathrm{Hg}$

Night DBP, $\mathrm{mm} \mathrm{Hg}$

Office SBP, $\mathrm{mm} \mathrm{Hg}$

Office DBP, $\mathrm{mm} \mathrm{Hg}$

$157.0 \pm 6.4$

$167.7 \pm 6.0 \quad 176.9 \pm 6.6$

$62.5 \pm 6.8$

$30.3(-54.7$ to -5.9$)$

$2.9(-21.6$ to 27.3$)$

Clinical

Protein excretion rate, $\mathrm{g} / 24 \mathrm{~h}$

eGFR, $\mathrm{mL} / \mathrm{min} / 1.73 \mathrm{~m}^{2}$

$129 \pm 1.1 \quad 125+12^{\mathrm{a}}$

$128 \pm 1.2$

$128 \pm 1.1$

$127 \pm 1.2$

$130 \pm 1.2$

$-2.2(-6.4$ to 1.9$)$

$76 \pm 0.7 \quad 74 \pm 0.8^{a}$

$75 \pm 0.8$

$76 \pm 0.7$

$76 \pm 0.8$

$77 \pm 0.8$

$-2.4(-5.1$ to 0.3$)$

$80 \pm 0.7 \quad 77 \pm 0.8$

$131 \pm 1.3$

$132 \pm 1.2$

$131 \pm 1.3$

$133 \pm 1.3$

$-2.9(-7.2$ to 1.4$)$

$\begin{array}{rrr}78 \pm 0.8 & 79 \pm 0.8 & 80 \pm 0.9\end{array}$

$80 \pm 0.9$

$-3.4(-6.3 \text { to }-0.6)^{b}$

$-2.1(-6.3$ to 2.1$)$

$120+1.2$

$117 \pm 1.4 \quad 120 \pm 1.4$

$120 \pm 1.3$

$121 \pm 1.4$

$-2.5(-7.3$ to 2.2$)$

$69 \pm 0.8 \quad 68 \pm 0.9$

$120 \pm 1.4$

$70 \pm 1.0$

$-0.9(-4.0$ to 2.2$)$

$-2.2(-4.9$ to 0.5$)$

$140 \pm 1.5 \quad 134 \pm 1.5^{\mathrm{c}}$

$69 \pm 0.9$
$133 \pm 1.6^{\circ}$

$69 \pm 0.9$

$139 \pm 1.6$

$-2.9(-8.3$ to 2.4$)$

$-2.3(-5.2$ to 0.5$)$

$85 \pm 0.9 \quad 80 \pm 0.9^{\mathrm{C}} \quad 81 \pm 0.9^{\mathrm{c}}$

$84 \pm 0.8$

$135 \pm 1.6$

$83 \pm 0.9$

$-1.8(-6.6$ to 3.0$)$

$-1.2(-4.3$ to 1.9$)$

$-5.2(-8.4 \text { to }-2.1)^{d}$

$-7.3(-12.7 \text { to }-1.9)^{d}$

$1.0 \pm 0.1$

$1.1 \pm 0.1$

$1.2 \pm 0.1$

$1.4 \pm 0.2^{a}$

$1.4 \pm 0.1^{\mathrm{a}}$

$-0.4(-0.7 \text { to }-0.1)^{\mathrm{d}}$

$-0.3(-0.6$ to -0.1$)$

$59.0 \pm 2.2$

$60.7 \pm 2.3$

$49.6 \pm 1.1$

$49.5 \pm 1.1$

$49.3 \pm 1.2$

$46.9 \pm 1.2^{2}$

-0.3 ( -2.9 to 2.3 )

$-2.2(-9.8$ to 5.4$)$

Total no. of anti-HTN medications

$2.3 \pm 0.2$

$2.3 \pm 0.2$

$2.3 \pm 0.2$

$2.3 \pm 0.2$

$59.8 \pm 2.4$

$-0.0(-0.3$ to 0.2$)$

$2.3(-0.4$ to 4.9$)$

Body weight, $\mathrm{kg}$

$89.8 \pm 0.4$

$-1.5(-2.7 \text { to }-0.3)^{b}$

$-0.0(-0.3$ to 0.2$)$

$91.4+0.3 \quad 91.4+0.4 \quad 91.5+0.4$

Psychosocial

HRQoL-Physical

$68.9 \pm 1.7$

$69.3 \pm 1.8$

$65.4 \pm 1.8$

$67.5 \pm 1.6$

$65.4 \pm 1.8$

$66.4 \pm 1.9$

2.4 ( -3.3 to 8.2$)$

$-1.7(-2.9$ to -0.5$)$

Self-efficacy

$7.6 \pm 0.1$

$8.1+0.1^{c}$

$7.9+0.1$

$7.8 \pm 0.1$

$7.8+0.1$

$74.9 \pm 1.7$

$2.3(-3.1$ to 7.7$)$

$-2.4(-8.2$ to 3.3$)$

Note: $\mathrm{n}=138$.

Abbreviations: BSA, body surface area; $\mathrm{Cl}$, confidence interval; $\mathrm{CL}_{c r}$, creatinine clearance; $\mathrm{DBP}$, diastolic blood pressure; eGFR, estimated glomerular filtration rate; HRQoL, health-related quality of life; HTN, hypertension; SBP, systolic blood pressure; T0, baseline; T1, 3 months' follow-up; T2, 6 months' follow-up.

a $P<0.05$; mean (standard error of mean) differs significantly from baseline.

${ }^{\mathrm{b}} P<0.05$; change in mean over time $(95 \% \mathrm{Cl})$ differs significantly from control group.

${ }^{\mathrm{c}} P<0.01$; mean (standard error of mean) differs significantly from baseline.

${ }^{\mathrm{d}} P<0.01$; change in mean over time $(95 \% \mathrm{Cl})$ differs significantly from control group. 

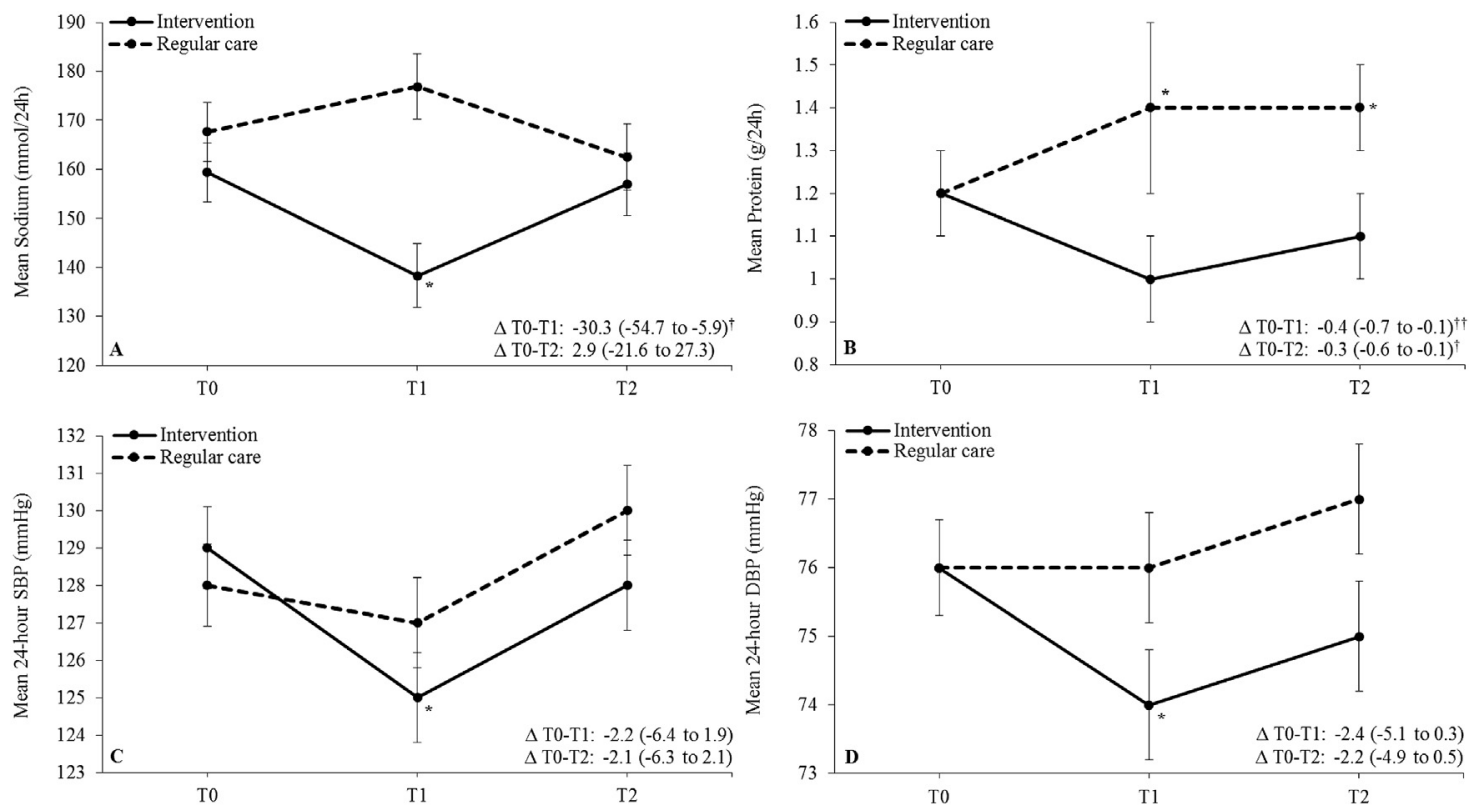

Figure 2. Within- and between-group effects of primary intention-to-treat analyses adjusted for baseline value: (A) sodium excretion, (B) protein excretion, (C) 24-hour systolic blood pressure (SBP), and (D) 24-hour diastolic blood pressure (DBP). ${ }^{*} P<0.05$, ${ }^{\star \star} P<0.01$; mean (standard error of mean) differs significantly from baseline. ${ }^{\dagger} P<0.05,{ }^{\dagger \dagger} P<0.01$; change in mean over time (95\% confidence interval) differs significantly from control group. Abbreviations: T0, baseline; T1, 3 months' follow-up; T2, 6 months' follow-up.

follow-up prompts. ${ }^{41}$ In our study, contact frequency was gradually reduced, but follow-up prompts (eg, postcards or booster sessions) were not included. Follow-up prompts have been associated with increased effectivity ${ }^{10}$; therefore, including an extended phase could have resulted in maintaining the low-sodium diet.

Similar to the literature, ${ }^{3,16,17,19}$ our sodium intervention also reduced BP. However, our ambulatory $\mathrm{BP}$ reductions did not remain significant at the 6month follow-up time and could be considered modest compared to the $8 / 2 \mathrm{~mm} \mathrm{Hg}$ reduction in 24hour BP by the self-management intervention of De Brito-Ashurst et al ${ }^{19}$ and the reduction of $9 / 4 \mathrm{~mm} \mathrm{Hg}$ (combining 24-hour and office measures) found by a recent meta-analysis. ${ }^{3}$ Discrepancies could be explained by study design (ie, the meta-analysis included many crossover studies and effectiveness was only measured directly after interventions) and the larger sodium intervention effects of $\sim 100 \mathrm{mmol} /$ $24 \mathrm{~h}$ found in these studies. ${ }^{3,19}$

In accordance with previous crossover studies, ${ }^{14-17}$ results showed that our intervention reduced protein excretion, but our effects (reductions of 0.4 and $0.3 \mathrm{~g} / 24 \mathrm{~h}$ at 3 and 6 months) seem small compared to the reduction of $0.8 \mathrm{~g} / 24 \mathrm{~h}$ found by Vogt et al, ${ }^{15}$ for example. However, the baseline protein excretion rate in our group was low compared to that in Vogt et al (ie, $1.2 \mathrm{vs} 3.8 \mathrm{~g} / 24 \mathrm{~h}$ ), and hence the percentage decrease in protein excretion could be considered comparable.
Furthermore, the literature suggests that reducing sodium intake could have beneficial effects on CKD progression. ${ }^{12,13}$ However, our study was underpowered to detect differences in kidney function and our follow-up was too short to confirm long-term beneficial effects. In line with this, no significant group differences were detected, although estimated glomerular filtration rates decreased in the control group.

In accordance with the literature, ${ }^{24}$ this intervention also increased patients' beliefs that they are capable of managing their kidney disease. However, contrary to Campbell et al, ${ }^{23}$ our intervention did not improve HRQoL. This discrepancy might be explained by patient characteristics; whereas Campbell et al included non-dialysis-dependent patients with advanced CKD with impaired HRQoL, we included patients with moderately decreased kidney function and relatively high HRQoL.

Finally, although not specified in the original protocol, a reduction in body weight was also observed in the intervention group. This finding corresponds partially with the literature; previous studies found decreased body weight after sodium interventions, ${ }^{15,36}$ but significant body weight reductions have not been found in the study by De Brito-Ashurst et $\mathrm{al}^{19}$ and a recent meta-analysis. ${ }^{3}$ An explanation for our intervention effect could be that the weight reduction was not sodium specific, but due to weight loss goals that $21(31 \%)$ participants set in addition to sodium goals. Unfortunately, objective 
markers of body composition were not collected to attribute this reduced body weight to either changes in body fat or fluid status.

Specific strengths of this study include a tailored intervention according to the needs of patients and health care professionals as assessed in a preparatory qualitative study ${ }^{5}$ and the application of multiple evidence-based behavior change techniques. ${ }^{7-11}$ Furthermore, because self-monitoring is a component of effective lifestyle interventions ${ }^{9,42}$ and patients with CKD have stressed the need for additional feedback regarding sodium, ${ }^{5}$ the inclusion of 2 sodium self-monitoring tools (ie, online diary and sodium measurement device) could be seen as a strength. However, patients also encountered problems with these self-monitoring tools, which might have hampered the effectiveness of this intervention (eg, negative feelings or less sodium feedback). Therefore, the inclusion of these self-monitoring tools could also be considered a study limitation. Another limitation is nonblinding; due to the active nature of the intervention, concealment of randomization was not possible. In addition, it is possible that trial participation and active recruitment caused both groups to reduce their sodium intakes prior to baseline measurements. This potential Hawthorne effect ${ }^{44}$ might have contributed to the modest effects found. Furthermore, this study has missing data that could possibly lead to biases. However, because clinical trials often deal with missing data, we performed intention-to-treat analyses to avoid overestimating intervention effects. ${ }^{45}$ To avoid biased estimates and loss of power, we also used linear mixed modeling and performed analyses while adjusting for imputed missing baseline values $(1.7 \%$ in the intervention group and $3.8 \%$ in the control group).$^{39}$ Our response rate could also be considered relatively low and hence limits generalization of results. However, similar response rates have been found in previous selfmanagement interventions (eg, $47 \%$ by Bucknall et $\mathrm{al}^{46}$ ). Finally, we included a heterogeneous group including patients who might have different renal responses to sodium restriction. However, recent studies have shown that sodium restriction also effectively reduced BP in patients who had received transplants ${ }^{47}$ and in patients with type 2 diabetic nephropathy. ${ }^{48}$ Moreover, inclusion of different patient groups could be considered a strength as well because patients under nephrologic care represent a highly heterogeneous group, and hence increases the generalizability of our results.

With this study, we report a small but important step to support patients with CKD in reducing sodium intake. However, additional research is needed to provide further insight into the intervention effects, for instance, the change in (amounts of) high- or low-sodium food products by means of food diary data. Furthermore, given that self-efficacy is associated with self-care behaviors, ${ }^{43,49}$ additional research is needed to investigate the mediating role of selfefficacy. Finally, future studies should also investigate whether the ESMO intervention effects could be improved by including a more robust and userfriendly sodium measurement device and a less complex online food diary, intensifying the intervention, involving patients' social environment, and adding booster sessions.

In conclusion, compared to regular care alone, this theory-based sodium self-management intervention modestly improved risk factors for disease progression in patients with CKD, although effects on sodium and ambulatory BP following the intervention diminished over time.

\section{ACKNOWLEDGEMENTS}

The ESMO Study Group comprises Sandra van Dijk, Yvette Meuleman, Friedo W. Dekker, Tiny Hoekstra, Gerjan Navis, Liffert Vogt, Paul J.M. van der Boog, Willem Jan W. Bos, Gert A. van Montfrans, Elisabeth W. Boeschoten, Marion Verduijn, Lucia ten Brinke, Anke Spijker, Arjan J. Kwakernaak, Jelmer K. Humalda, Tonnie van Hirtum, Robin Bokelaar, Marie-Louise Loos, Anke Bakker-Edink, Charlotte Poot, Yvette Ciere, Sophie Zwaard, Glenn Veldscholte, Lara Heuveling, Marjolein Storm, and Karen Prantl.

We thank all patients participating in the ESMO study. We are also grateful for the support by the staff of participating centers, Medimate, Bonstato, the research nurse and data managers at Nefrovisie, and the entire ESMO Study Group.

Support: The present study was supported by grants from The Netherlands Organization for Health Research and Development-Medical Sciences (ZonMw: 300020016) and the Dutch Kidney Foundation (SB93). They had no role in the study design (collecting, analysis or interpretation of data), writing of the paper, and the decision to submit the paper for publication.

Financial Disclosure: The authors declare that they have no other relevant financial interests.

Contributors: Research idea and study design: YM, FWD, SvD; data acquisition: YM, TH; statistical analysis: YM, TH, FWD; data interpretation: YM, TH, FWD, GN, LV, PJMvdB, WJWB, GAvM, SvD; supervision or mentorship: YM, TH, FWD, SvD. Each author contributed important intellectual content during manuscript drafting or revision and accepts accountability for the overall work by ensuring that questions pertaining to the accuracy or integrity of any portion of the work are appropriately investigated and resolved. SvD takes responsibility that this study has been reported honestly, accurately, and transparently; that no important aspects of the study have been omitted; and that any discrepancies from the study as planned and registered have been explained.

Peer Review: Evaluated by 2 external peer reviewers, a Statistical Editor, a Co-Editor, and Editor-in-Chief Levey.

\section{SUPPLEMENTARY MATERIAL}

Figure S1: Within- and between-group effects of primary intention-to-treat analyses adjusted for baseline values.

Item S1: Content and fidelity of intervention based on CALORE Taxonomy.

Item S2: Sensitivity analyses. 
Note: The supplementary material accompanying this article (http://dx.doi.org/10.1053/j.ajkd.2016.08.042) is available at www.ajkd.org

\section{REFERENCES}

1. Nederlanse federatie voor Nefrologie. Richtlijn voor de behandeling van patienten met Chronische Nierschade (CNS). 2009. http://www.cardiometabool.nl/wp-content/uploads/2013/07/richtlijn 2009_Behandeling-van-patienten-met-Chronische-nierschade.pdf. Accessed August 21, 2016.

2. Humalda JK, Navis G. Dietary sodium restriction: a neglected therapeutic opportunity in chronic kidney disease. Curr Opin Nephrol Hypertens. 2014;23(6):533-540.

3. McMahon EJ, Campbell KL, Bauer JD, Mudge DW. Altered dietary salt intake for people with chronic kidney disease. Cochrane Database Syst Rev. 2015;2:CD010070.

4. Krikken JA, Laverman GD, Navis G. Benefits of dietary sodium restriction in the management of chronic kidney disease. Curr Opin Nephrol Hypertens. 2009;18(6):531-538.

5. Meuleman Y, Ten Brinke L, Kwakernaak AJ, et al. Perceived barriers and support strategies for reducing sodium intake in patients with chronic kidney disease: a qualitative study. Int J Behav Med. 2015;22(4):530-539.

6. De Brito-Ashurst I, Perry L, Sanders TA, Thomas JE, Yaqoob MM, Dobbie H. Barriers and facilitators of dietary sodium restriction amongst Bangladeshi chronic kidney disease patients. J Hum Nutr Diet. 2011;24(1):86-95.

7. Maes S, Karoly P. Self-regulation assessment and intervention in physical health and illness: a review. Appl Psychol. 2005;54(2):267-299.

8. Haynes RB, Ackloo E, Sahota N, McDonald HP, Yao X. Interventions for enhancing medication adherence. Cochrane Database Syst Rev. 2008;2:CD000011.

9. Michie S, Abraham C, Whittington C, McAteer J, Gupta S. Effective techniques in healthy eating and physical activity interventions: a meta-regression. Health Psychol. 2009;28(6): 690-701.

10. Lara J, Hobbs N, Moynihan PJ, et al. Effectiveness of dietary interventions among adults of retirement age: a systematic review and meta-analysis of randomized controlled trials. BMC Med. 2014;12:60.

11. Greaves CJ, Sheppard KE, Abraham C, et al. Systematic review of reviews of intervention components associated with increased effectiveness in dietary and physical activity interventions. BMC Public Health. 2011;11:119.

12. Lambers Heerspink HJ, Holtkamp FA, Parving HH, et al. Moderation of dietary sodium potentiates the renal and cardiovascular protective effects of angiotensin receptor blockers. Kidney Int. 2012;82(3):330-337.

13. Vegter S, Perna A, Postma MJ, Navis G, Remuzzi G, Ruggenenti P. Sodium intake, ACE inhibition, and progression to ESRD. J Am Soc Nephrol. 2012;23(1):165-173.

14. Slagman MC, Waanders F, Hemmelder MH, et al. Moderate dietary sodium restriction added to angiotensin converting enzyme inhibition compared with dual blockade in lowering proteinuria and blood pressure: randomised controlled trial. BMJ. 2011;343:d4366.

15. Vogt L, Waanders F, Boomsma F, de Zeeuw D, Navis G. Effects of dietary sodium and hydrochlorothiazide on the antiproteinuric efficacy of losartan. J Am Soc Nephrol. 2008;19(5): 999-1007.

16. Campbell KL, Johnson DW, Bauer JD, et al. A randomized trial of sodium-restriction on kidney function, fluid volume and adipokines in CKD patients. BMC Nephrol. 2014;15:57.
17. McMahon EJ, Bauer JD, Hawley CM, et al. A randomized trial of dietary sodium restriction in CKD. J Am Soc Nephrol. 2013;24(12):2096-2103.

18. Elliott P, Brown IJ. Sodium intakes around the world. Background document prepared for the Forum and Technical Meeting on Reducing Salt Intake in Populations (Paris 5-7th October 2006). http://www.who.int/dietphysicalactivity/Elliotbrown-2007.pdf. Accessed August 21, 2016.

19. De Brito-Ashurst I, Perry L, Sanders TA, et al. The role of salt intake and salt sensitivity in the management of hypertension in South Asian people with chronic kidney disease: a randomised controlled trial. Heart. 2013;99(17):1256-1260.

20. Van Zuilen AD, Blankestijn PJ, van Buren M, et al. Nurse practitioners improve quality of care in chronic kidney disease: two-year results of a randomised study. Neth J Med. 2011;69(11): 517-526.

21. Leventhal H, Meyer D, Nerenz D, Rachman S. The common sense representation of illness danger. In: Rachman S (ed). Contributions to Medical Psychology. Vol. 2. New York, NY: Pergamon Press; 1980:7-30.

22. Leventhal H, Brissette I, Leventhal EA. The common-sense model of self-regulation of health and illness. In: Cameron LD, Leventhal H (eds). The Self-Regulation of Health and Illness Behaviour. London, England: Routledge; 2003:42-65.

23. Campbell KL, Ash S, Bauer JD. The impact of nutrition intervention on quality of life in pre-dialysis chronic kidney disease patients. Clin Nutr. 2008;27(4):537-544.

24. Lin CC, Tsai FM, Lin HS, Hwang SJ, Chen HC. Effects of a self-management program on patients with early-stage chronic kidney disease: a pilot study. Appl Nurs Res. 2013;26(3): 151-156.

25. Schulz KF, Altman DG, Moher D. CONSORT 2010 statement: updated guidelines for reporting parallel group randomised trials. PLoS Med. 2010;7(3):e1000251.

26. National Kidney Foundation. K/DOQI clinical practice guidelines for chronic kidney disease: evaluation, classification, and stratification. Am J Kidney Dis. 2002;39(2)(suppl 1):S1-S266.

27. Kidney Disease: Improving Global Outcomes (KDIGO) CKD Work Group. KDIGO 2012 clinical practice guideline for the evaluation and management of chronic kidney disease. Kidney Int Suppl. 2013;3:1-150.

28. Rollnick S, Miller WR, Butler CC. Motivational Interviewing in Health Care. Helping Patients Change Behavior. New York, NY: Guilford Press; 2008.

29. Staal S, Ungerer $M$, Floris $A$, et al. A versatile electrophoresis-based self-test platform. Electrophoresis. 2015;36(5):712-721.

30. Michie S, Ashford S, Sniehotta FF, Dombrowski SU, Bishop A, French DP. A refined taxonomy of behaviour change techniques to help people change their physical activity and healthy eating behaviours: the CALO-RE taxonomy. Psychol Health. 2011;26(11):1479-1498.

31. Parati G, Stergiou G, O'Brien E, et al. European Society of Hypertension practice guidelines for ambulatory blood pressure monitoring. J Hypertens. 2014;32(7):1359-1366.

32. Du Bois D, Du Bois EF. A formula to estimate the approximate surface area if height and weight be known. 1916 . Nutrition. 1989;5(5):303-311.

33. Levey AS, Greene T, Kusek JW, Beck GJ. A simplified equation to predict glomerular filtration rate from serum creatinine [abstract]. J Am Soc Nephrol. 2000;11:155A.

34. Ware JE, Sherbourne CD. The MOS 36-Item Short-Form Health Survey (SF-36). I. Conceptual framework and item selection. Med Care. 1992;30(6):473-483. 
35. Lorig K, Stewart A, Ritter P, González V, Laurent D, Lynch J. Outcome Measures for Health Education and Other Health Care Interventions. Thousand Oaks, CA: Sage Publications; 1996.

36. Krikken JA, Dallinga-Thie GM, Navis G, Dullaart RP. Short term dietary sodium restriction decreases HDL cholesterol, apolipoprotein A-I and high molecular weight adiponectin in healthy young men: relationships with renal hemodynamics and RAAS activation. Nutr Metab Cardiovasc Dis. 2012;22(1): $35-41$.

37. Khosla N, Bakris G. Lessons learned from recent hypertension trials about kidney disease. Clin J Am Soc Nephrol. 2006;1:229-235.

38. Stergiou GS, Baibas NM, Gantzarou AP, et al. Reproducibility of home, ambulatory, and clinic blood pressure: implications for the design of trials for the assessment of antihypertensive drug efficacy. Am J Hypertens. 2002;15(2):101-104.

39. Montez-Rath ME, Winkelmayer WC, Desai M. Addressing missing data in clinical studies of kidney diseases. Clin J Am Soc Nephrol. 2014;9(7):1328-1335.

40. Cook NR, Kumanyika SK, Cutler JA, Whelton PK. Doseresponse of sodium excretion and blood pressure change among overweight, nonhypertensive adults in a 3-year dietary intervention study. J Hum Hypertens. 2005;19(1):47-54.

41. Lasser VI, Raczynski JM, Stevens VJ, et al. Trials of Hypertension Prevention, phase II. Structure and content of the weight loss and dietary sodium reduction interventions. Ann Epidemiol. 1995;5(2):156-164.

42. Janssen V, De Gucht V, Dusseldorp E, Maes S. Lifestyle modification programmes for patients with coronary heart disease: a systematic review and meta-analysis of randomized controlled trials. Eur J Prev Cardiol. 2013;20(4):620-640.

43. Clark S, Farrington K, Chilcot J. Nonadherence in dialysis patients: prevalence, measurement, outcome, and psychological determinants. Semin Dial. 2014;27(1):42-49.

44. McCambridge J, Witton J, Elbourne DR. Systematic review of the Hawthorne effect: new concepts are needed to study research participation effects. J Clin Epidemiol. 2014;67(3):267-277.

45. Armijo-Olivo S, Warren S, Magee D. Intention to treat analysis, compliance, drop-outs and how to deal with missing data in clinical research: a review. Phys Ther Rev. 2009;14(1):36-49.

46. Bucknall CE, Miller G, Lloyd SM, et al. Glasgow supported self-management trial (GSuST) for patients with moderate to severe COPD: randomised controlled trial. BMJ. 2012;344:e1060.

47. De Vries LV, Dobrowolski LC, van den Bosch JJ, et al. Effects of sodium restriction in renal transplant recipients on RAAS blockade: a randomized clinical trial. Am J Kidney Dis. 2016;67(6):936-944.

48. Kwakernaak AJ, Krikken JA, Binnenmars SH, et al. Effects of sodium restriction and hydrochlorothiazide on RAAS blockade efficacy in diabetic nephropathy: a randomised clinical trial. Lancet Diabetes Endocrinol. 2014;2(5):385-395.

49. Curtin RB, Walters BA, Schatell D, Pennell P, Wise M, Klicko K. Self-efficacy and self-management behaviors in patients with chronic kidney disease. Adv Chronic Kidney Dis. 2008;15(2): 191-205.

50. ERA-EDTA Registry. ERA-EDTA Registry Annual Report 2009. Amsterdam, the Netherlands: Academic Medical Center, Department of Medical Informatics; 2011. 